\title{
КЛИНИКО-НЕЙРОФИЗИОЛОГИЧЕСКИЕ ОСНОВЫ ПРИМЕНЕНИЯ КВАНТОВОЙ ТЕРАПИИ В ЛЕЧЕНИИ БОЛЬНЫХ С НЕЙРОПАТИЯМИ ЛИЦЕВОГО НЕРВА
}

Гусейнова С.Г., Мурадов Р.В. НИИ медицинской реабилитаџии, Баку, Азербайджкан

Невропатии лицевого нерва (НЛН) занимают особое место среди заболеваний периферической нервной системы. Число больных с этой патологией в последние годы неуклонно увеличивается. Так, на поражение лицевого нерва приходится $11,8 \%$ всех заболеваний ПНС и 38\% мононейропатий (Смирнов В.А., 1976). Несмотря на успехи, достигнутые в последние годы в установлении патогенеза и разработке методов лечения НЛН, в настоящее время имеется большое количество пациентов, страдающих остаточными явлениями и осложнениями заболевания.

Поиск нового патогенетически обоснованного восстановительного лечения НЛН, а также профилактики ее осложнений - контрактур и синкинезий, остается актуальной на современном этапе нейрореабилитации. В связи с этим реабилитационные мероприятия у данного контингента больных должна включать последовательную лечебную программу с учетом стадии, сроков давности заболевания, выраженности клинических проявлений и быть направлены на предупреждение развития лицевых контрактур и их лечение (Юдельсон Ю.С., 1980; Сергеев В.В., 1998; Черникова Л.А., 2003; Гусева В.И. и др., 2004).

В настоящее время в клинической практике для лечения заболеваний периферической нервной системы широко используется квантовая терапия. Особое место в ряду современных медицинских технологий занимает аппарат квантовой терапии РИКТА02 (М2), в котором оказывают лечебное воздействие одновременно несколько излучений, а именно: импульсное лазерное излучение инфракрасного диапазона, пульсирующее широкополосное инфракрасное излучение, красный свет и, наконец, постоянное слабое магнитное поле. Доказано, что одновременное воздействие различных излу- чений дает усиленный лечебный эффект по сравнению с тем, когда эти излучения используются отдельно. Лечение с помощью аппарата квантовой терапии совместимо с лекарственной терапией. Однако до настоящего времени эффективность применения квантовой терапии у больных с нейропатией лицевого нерва остается малоизученной. В доступной литературе отсутствуют сведения о клинико-нейрофизиологических механизмах действия квантовой терапии у больных с нейропатией лицевого нерва.

Цель исследования - изучение эффективности квантовой терапии в лечении больных с нейропатией лицевого нерва на основе клинико-нейрофизиологических методов оценки.

\section{Материалы и методы исследования}

Проведено клинико-электромиографическое обследование 35 больных с нейропатией лицевого нерва (НЛН). Глобальную электромиографию (ЭМГ) проводили до и после лечения, при этом регистрировали суммарную биоэлектрическую активность (БА) мимических мышщ больной и здоровой стороны. Запись электромиограмм проводили в покое мышц и при их максимальном произвольном сокращении. Обследованию подвергались следующие мышцы: m. frontalis, m. orbicularis oculi, m. nazalis, m.orbicularis oris. Больные получали двухэтапное лечение: на первом этапе проводилась квантовая терапия от аппарата РИКТА (торговая марка Витязь, Россия) на пораженную половину лица и по ходу ветвей лицевого нерва и область сосцевидного отростка. При наличии болевого синдрома использовали частоту 1000 Гц и 50 Гц по 1 минуте, при тяжелой степени прозопареза - 5 Гц по 2 минуты. На втором этапе лечения больные получали массаж и лечебную гимнастику.

Результаты и их обсуждение

Ведущим проявлением в клинике НЛН 
являлся парез мимической мускулатуры, вследствие этого все больные предъявляли жалобы на асимметрию лица. У $31 \%$ больных был диагностирован ишемический прозопарез, развившиеся на фоне церебральнососудистого криза или значительного повышения артериального давления. Инфекционные нейропатии были выявлены у 26,5\% больных, отогенные нейропатии - у $3,5 \%$ больных, идиопатические нейропатии - у 13,5\% больных. У остальных больных выявлялось несколько причин заболевания. Длительность заболевания колебалась от 7 дней до 2-х лет. Тяжелая степень заболевания выявлялась у 47,8\% больных, средняя степень у $32,9 \%$, легкая степень - у 19,3\% больных.

При поверхностной ЭМГ в исходном состоянии у больных с НЛН были выявлены нарушения биоэлектрической активности мышц. В режиме покоя у обследованных больных регистрировались низкоамплитудные колебания, лишь в 5 случаях выявлялось повышение активности покоя в виде острых положительных потенциалов, амплитуда которых колебалась в пределах 50-100 мкВ, что указывало на наличие грубых дегенеративных изменений в нервных стволах. Оценкой ЭМГ в режиме произвольного максимального сокращения были выявлены качественные и количественные изменения биопотенциалов мышц. При произвольном максимальном сокращении у $12,7 \%$ больных отмечалось отсутствие биоэлектрической активности мышц, которое соответствует IV типу ЭМГ («биоэлектрическое молчание») согласно классификации Ю.С. Юсевич и отмечалось у больных с тяжелой степенью заболевания. У этих больных при ЭНМГ обследовании выявлялось отсутствие проводимости по двигательным волокнам пораженного лицевого нерва. У подавляющего большинства больных с нейропатией лицевого нерва отмечалось снижение амплитуды биоэлектрической активности мышц, получавших иннервацию, как с верхней ветви, так и с нижней ветви. Так, средняя величина амплитуды биопотенциалов составила для $\mathrm{m}$. frontalis $97,4 \pm 3,2 \mathrm{mkV}, \mathrm{m}$. orbicularis oculi $101,8 \pm 6,3 \mathrm{mkV}$, m. nazalis - 73,6 $\pm 4,2 \mathrm{mkV}$ i dlə m.orbicularis oris $-106,7 \pm 8,5 \mathrm{mkV}$.

Анализом исходных ЭМГ, регистрируемых в режиме максимального произвольного сокращения, была установлена зависимость выявленных количественных изменений от степени и уровня поражения нервного ствола. Как видно из данных, представленных в табл. 1, снижение амплитуды биопотенциалов мышц было высокодостоверным при супрагеникулярном поражении лицевого нерва. Сравнительный анализ результатов ЭМГ исследования показал наличие наиболее выраженных изменений при тяжелых формах и при затяжном течении нейропатии лицевого нерва.

Таблица 1. Среднее значение амплитуды биопотенциалов мышц при различных уровнях поражения нервного ствола $(\mathrm{M} \pm \mathrm{M})$

\begin{tabular}{|l|l|l|l|}
\hline Уровни поражения & $\begin{array}{l}\text { Супрагеникулярное } \\
\text { поражение } \\
(\mathrm{n}=17)\end{array}$ & $\begin{array}{l}\text { Инфрагеникулярное } \\
\text { поражение } \\
(\mathrm{n}=18)\end{array}$ & $\begin{array}{l}\text { Контроль } \\
(\mathrm{n}=18)\end{array}$ \\
\hline m. frontalis & $\frac{97,4 \pm 3,2^{* * *}}{107,5 \pm 4,5^{*}}$ & $\frac{103,5 \pm 3,8^{* * *}}{132,7 \pm 6,4}$ & $125,6 \pm 5,7$ \\
m. orbicularis oculi & $\frac{101,8 \pm 6,3^{* * *}}{113,7 \pm \pm 5,8 * * *}$ & $131,8 \pm 6,5$ \\
m. nazalis & $\frac{73,6 \pm 4,2^{* * *}}{139,7 \pm 7,3}$ & $\frac{83,5 \pm 3,9 * * *}{115,7 \pm 6,6}$ & $127,8 \pm 7,2$ \\
m. orbicularis oris & $\frac{93,5 \pm 5,7^{* * *}}{109,6 \pm 4,5^{*}}$ & $\frac{106,7 \pm 8,5}{112,7 \pm 6,4}$ & $137,9 \pm 8,5$ \\
\hline
\end{tabular}

Примечание: p- достоверность высчитана по сравнению с данными контрольной группы. * - p<0,1; ** $\Pi<0,01 ; * * *$ - п<0,001. В числителе - показатели пораженной стороны, в знаменателе - интактной стороны. 
После курса квантотерапии отмечался регресс двигательных нарушений, уменьшение асимметрии лица, болезненных ощущений и мышечных уплотнений в области лица, болезненного стягивания. Анализ динамики обратного развития неврологических симптомов показал, что при лицевой невропатии легкой степени двига- тельные нарушения уменьшились в 63,9\% наблюдений. У больных лицевой нейропатией средней степени выраженности отмечен более медленный регресс пареза. Динамика двигательных нарушений у больных с тяжелой лицевой нейропатией была невыраженной и проявлялась незначительным регрессом пареза.

Таблица 2. Динамика амплитуды биопотенциалов мышц под влиянием лечения (М士м; н=27)

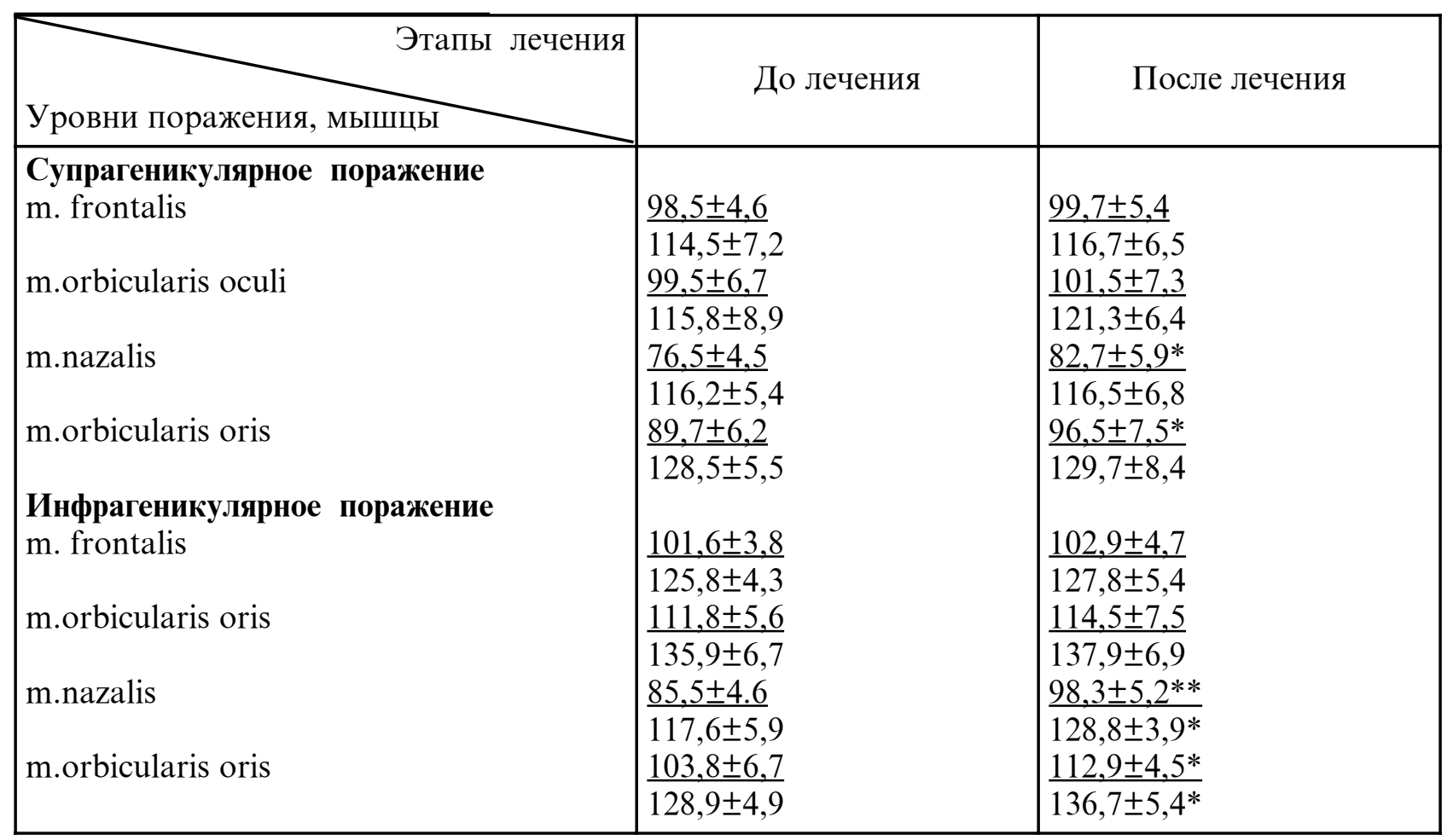

Примечание: $\mathrm{p}$ - достоверность высчитана по сравнению с исходными данными. ${ }^{*}$ - p $<0,1 ;{ }^{* *}$ - п<0,01; В числителе - показатели пораженной стороны, в знаменателе - интактной стороны.

Электромиографические исследования, проведенные до и после лечения, показали положительную динамику исходно выявленных качественных и количественных изменений электромиограмм (табл.2). Качественные изменения проявлялись насыщением ЭМГ, уменьшением активности покоя. Количественная обработка ЭМГ максимального сокращения показала нарастание амплитуды биопотенциалов в той или иной степени во всех мышцах в процессе лечения. У больных после первого этапа лечения выявлялось тенденция к повышению амплитуды биопотенциалов м. назалис и м. орбиъуларис орис $(\mathrm{p}<0,1)$ лишь при инфрагеникулярном поражении нервного ствола. После второго этапа лечения у больных этой группы наблюдали достоверное нарастание амплитуды био-

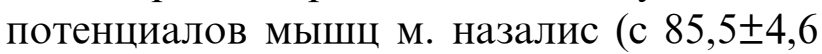
до $98,3 \pm 5,2$ мкВ; p<0,01) и м. орбиъуларис

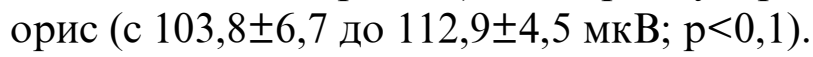

Таким образом, полученные результаты свидетельствуют о том, что квантовая терапия является эффективным методом лечения больных с нейропатией лицевого нерва. Комплексное применение квантовой терапии оказывает благоприятное влияние на клиническое течение заболевания, биоэлектрическую активность и электрогенез 
мышц, что расширяет арсенал средств немедикаментозной терапии на различных

\section{ЛИТЕРАТУРА}

1. Гусева В.И., Горелова Ю.В., Зайцев А.А. и др. Восстановительное лечение больных с периферическими невропатиями лицевого нерва: http://medtsu.tula.ru/VNMT/Archive/2004/n4/p64.htm 2. Сергеев В.В. Оптимизация диагностики и лечения невропатии лицевого нерва в остром и восстановительном периодах: Автореф. дис. ... к.м.н. Москва, 1998. - 16с.

3. Смирнов В.А. Заболевания нервной системы. М.: Медицина, 1976. - 239c.

4. Пузин М.Н., Разинкин О.П., Рушанов М. И. Не- этапах лечебно-восстановительных мероприятий у данного контингента больных.

вропатия лицевого нерва // Журн. невропатологии и психиатрии. - 1991. - №5. - С.112-115.

5. Черникова Л.А. Современное состояние физической нейрореабилитации и перспективы ее развития // Физиотерапия, бальнеология, реабилитация. 2003, №6. - С. 3-6.

6. Юдельсон Я.Б. и др. Эффективность местного применения лидазы и трилона Б при неврите лицевого нерва и его осложнениях // Сбор. научн. Трудов СГМИ. - Смоленск, 1984. - С. 83-85.

7. Юдельсон Я.Б. Вторичная контрактура мимических мышц. - Смоленск: СГМИ, 1994. - 138с.

\title{
РЕЗЮМЕ
}

\section{КЛИНИКО-НЕЙРОФИЗИОЛОГИЧЕСКИЕ ОСНОВЫ ПРИМЕНЕНИЯ КВАНТОВОЙ ТЕРАПИИ В ЛЕЧЕНИИ БОЛЬНЫХ С НЕЙРОПАТИЯМИ ЛИЦЕВОГО НЕРВА}

\author{
Гусейнова С.Г., Мурадов Р.В. \\ НИИ медицинской реабилитации, Баку, Азербайджан
}

Изучено эффективность квантовой терапии в лечении больных с нейропатией лицевого нерва на основе клинико-нейрофизиологических методов оценки. Установлено, что квантовая терапия является эффективным методом лечения больных с нейропатией лицевого нерва. Выявлено, что комплексное применение квантовой терапии оказывает благоприятное влияние на клиническое течение заболевания, биоэлектрическую активность и электрогенез мышц, что расширяет арсенал средств немедикаментозной терапии на различных этапах лечебно-восстановительных мероприятий у данного контингента больных.

\section{SUMMARY}

\section{CLINICONEUROPHYSIOLOGICAL PRINCIPLES OF QUANTUM THERAPY IN THE TREATMENT OF PATIENTS SUFFERING FROM FACIAL NERVE NEUROPATHY}

\author{
S.G. Huseynova, R.B. Muradov \\ Research Institute of Medical Rehabilitation, Baku, Azerbaijan
}

In our study we wanted to assess the efficacy of quantum therapy in the treatment of patients suffering from facial nerve neuropathy, based on cliniconeurophysiological methods of evaluation. It was shown that quantum therapy is an effective method of a patient's treatment suffering from facial nerve neuropathy. It was proved that complex use of quantum therapy seems to have a favourable effect on clinical course of a disease, bioelectrical activity and electrogenesis of muscles. And this, in its turn, widens the arsenal of ways of non-medicamentous therapy on various stages of treatment and restorative measures in this contingent of patients. 